single histopathologic entity: an analysis of 32 cases and a comprehensive review of the literature. Am J Surg Pathol. 2004;28:1-30.

2. Jonsson KB, Zahradnik R, Larsson $\mathrm{T}$, White KE, Sugimoto T, Imanishi $\mathrm{Y}$, et al. Fibroblast growth factor 23 in oncogenic osteomalacia and X-linked hypophosphatemia. N Engl J Med. 2003;348: 1656-63.

3. Weidner N, Santa Cruz D. Phosphaturic mesenchymal tumors. A poly- morphous group causing osteomalacia or rickets. Cancer. 1987;59: 1442-54.

4. Seufert J, Ebert K, Muller J, Eulert J, Hendrich C, Werner E, et al. Octreotide therapy for tumor-induced osteomalacia. $N$ Engl $\mathrm{J}$ Med. 2001;345:1883-8.

5. Carpenter TO. Oncogenic osteomalacia-a complex dance of factors. N Engl J Med. 2003;348:1705-8.

\title{
Staged closure of tracheogastrocutaneous fistula after esophagectomy for infiltrative granular cell tumor
}

\author{
Robert Merritt, MD, ${ }^{a}$ Steven M. Zeitels, MD, ${ }^{a}$ William G. Austen, Jr, MD, ${ }^{a}$ Gregory Y. Lauwers, MD, ${ }^{b}$ and \\ Henning A. Gaissert, MD, ${ }^{a}$ Boston, Mass
}

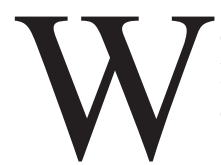

e report a tracheogastrocutaneous fistula and bilateral vocal cord paralysis after resection of an esophageal tumor. Reconstruction in 2 stages restored voice and swallowing.

\section{Clinical Summary}

A 22-year-old woman with a normal voice presented with a 3-year history of progressive dysphagia to solids and choking. A computed tomographic scan (Figure 1) showed a $3.8 \times 1.7-\mathrm{cm}$ esophageal wall mass compressing the trachea. A submucosal mass was found on endoscopy; biopsy was nondiagnostic. A cervical incisional biopsy specimen was interpreted as a benign granular cell tumor (GCT). The patient sought a second opinion and underwent neck re-exploration with tracheostomy. A second biopsy specimen was read as a malignant GCT. The mass was resected during a third procedure by dividing the trachea to provide access for total esophagectomy and posterior window resection of the trachea. After esophageal anastomosis in the neck to stomach, the cartilaginous trachea was closed and tracheal continuity was restored. The patient awoke hoarse from the operation. One week later, a fistula presented between the trachea and esophageal anastomosis.

In 4 additional procedures, skin flaps from the neck and left forearm were raised to close the fistula in the tracheal stoma, each of which was unsuccessful. The final attempt at closure 5 months after resection included division of the trachea with closure of the larynx and cutaneous end stoma. She presented to Massachusetts General Hospital requiring constant suction of gastric secretions from the tracheal stoma. Bilateral vocal cord palsy was noted on

From the Departments of Surgery ${ }^{\mathrm{a}}$ and Pathology, ${ }^{\mathrm{b}}$ Massachusetts General Hospital, Harvard Medical School, Boston, Mass.

Received for publication Feb 28, 2007; revisions received May 14, 2007; accepted for publication May 23, 2007.

Address for reprints: Henning A. Gaissert, MD, Massachusetts General Hospital, Blake 1570, Fruit St, Boston, MA 02114 (E-mail: hgaissert@partners.org).

J Thorac Cardiovasc Surg 2007;134:805-7

$0022-5223 / \$ 32.00$

Copyright $@ 2007$ by The American Association for Thoracic Surgery doi:10.1016/j.jtcvs.2007.05.029 laryngoscopy, and the subglottic lumen was closed below the cricoid. The 3-cm-long native esophagus ended in the 2-cm-wide fistula between the gastric mucosa and the membranous portion of the trachea. Gastric secretions freely washed into the trachea and drained from the cutaneous stoma. The residual trachea was $7 \mathrm{~cm}$ long, with inflamed mucosa.

The first stage of reconstruction closed the fistula 1 year after esophagectomy (Figure 2). By using a cervicomediastinal approach, the stomach was separated from the trachea, closed in the posterior mediastinum, and covered with pectoral muscle. Intestinal continuity was restored with substernal colon and colojejunostomy. Evaluation after recovery showed persistent vocal cord palsy in midabduction but no aspiration. The patient maintained her weight on an oral diet.

For tracheal reconstruction 5 months later, the cricoid was opened, and the distal trachea was mobilized for end-to-end anastomosis. After intubation for 3 days, a small tracheostomy was placed. The patient was discharged without stridor, leaving a stomal stent that was removed 4 months later. The patient now has a well-modulated voice without hoarseness. An uneventful lower body lift under endotracheal anesthesia has since been performed for cosmetic reasons.

Histologic review of the outside specimen at Massachusetts General Hospital established an infiltrative GCT of the esophagus (Figure 3). The tumor extensively involved the muscularis propria and adventitia and was present at the cervical and soft tissue

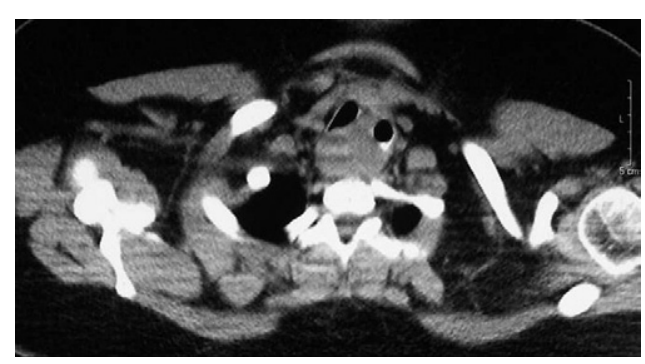

Figure 1. Computed tomographic scan demonstrates a cervical mass displacing both the tracheal and esophageal lumen. 

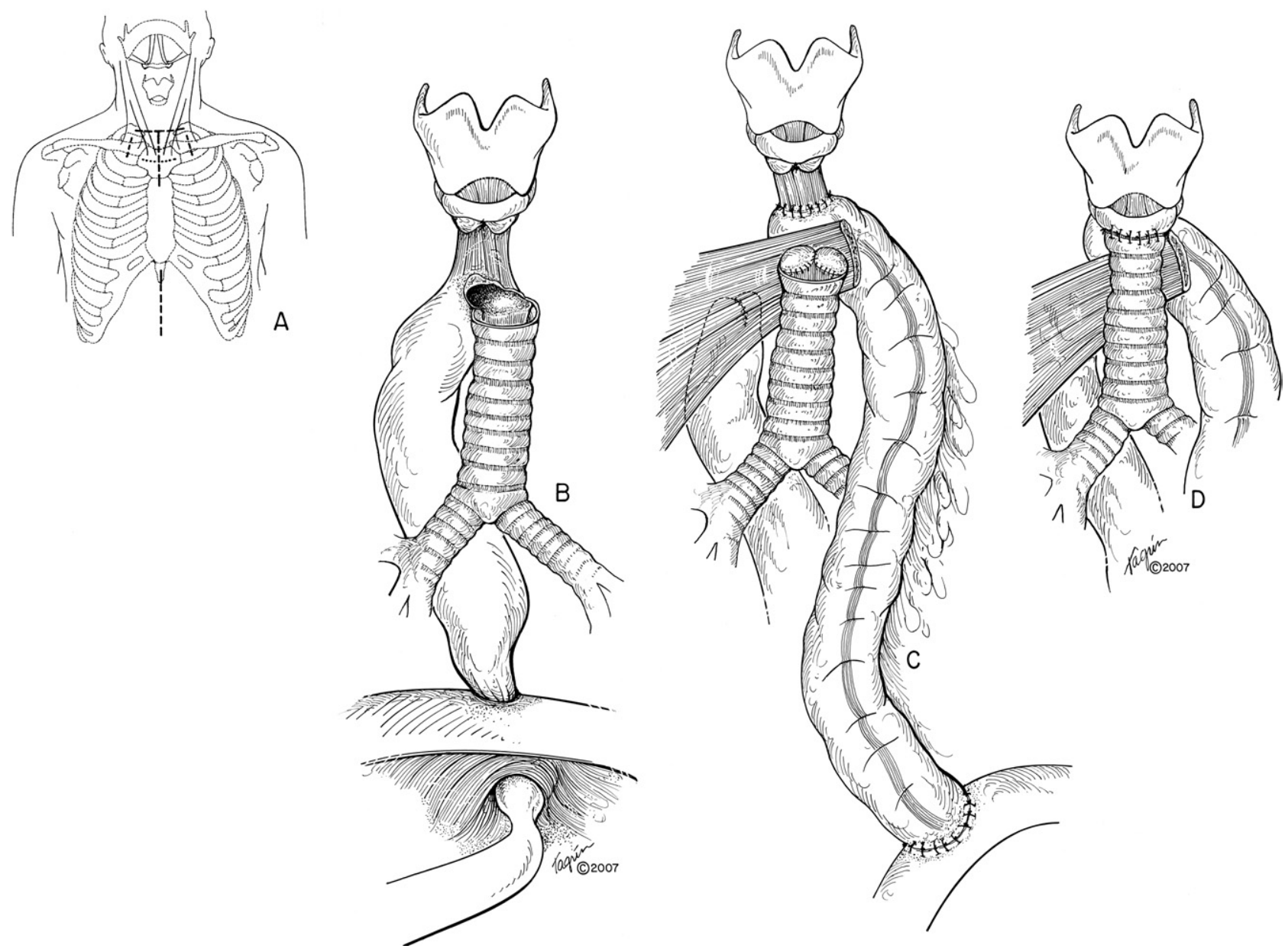

Figure 2. A, Incisions for first stage of reconstruction with extent of clavicular and manubrial resection. B, Location of fistula. C, Result of reconstruction after the first stage. D, Result of reconstruction after the second stage.

margin. Tracheal invasion was not identified. The tumor consisted of polygonal to spindle cells with large nuclei and nucleoli without mitoses or necrosis.

\section{Discussion}

GCTs occur in 3 grades: the most frequent is the second most common benign esophageal tumor. Only 3 cases of malignant GCTs are reported. Infiltrative tumors are of intermediate differentiation, with 15 known cases. ${ }^{1}$ Mean patient age was 40 years, and dysphagia was the most common symptom. Tumors measuring up to $3 \mathrm{~cm}$ were located in the upper esophagus and infiltrated to the muscularis propria in 7 patients, the adventitia in 4 patients, and the regional organs (trachea, pharynx, or larynx) in 4 patients. ${ }^{1-5}$ No metastasis or death was reported; extended survival (in 1 patient more than 22 years after incomplete surgical excision 2) was the rule.

Infiltrative GCTs do not require radical resection. Conservative organ-sparing extirpation close to the tumor preserves adjacent structures. Preservation of at least half of the esophageal circumference allows primary closure without esophagectomy. Dividing the trachea to access the cervical esophagus has important disadvantages. Total esophagectomy renders the trachea ischemic; the anastomosis is destined to fail in almost all combined resections of the trachea and esophagus. Suture lines not separated by vascularized tissue are also liable to erosion and fistulization. Side-to-side closure of the trachea after large window resection must produce stenosis at best. The alternative of a short segmental tracheal and esophageal resection preserves the lateral blood supply.

Tracheal reconstruction subsequent to bilateral vocal cord injury exposes the patient to aspiration and airway obstruction. In our case, however, neither bedside evaluation nor modified barium swallow identified laryngeal penetration of food. Stridor after reconstruction resolved within 1 week after temporary tracheostomy. The patient, of course, remains at risk of aspiration or obstruction and requires future observation for these events. 


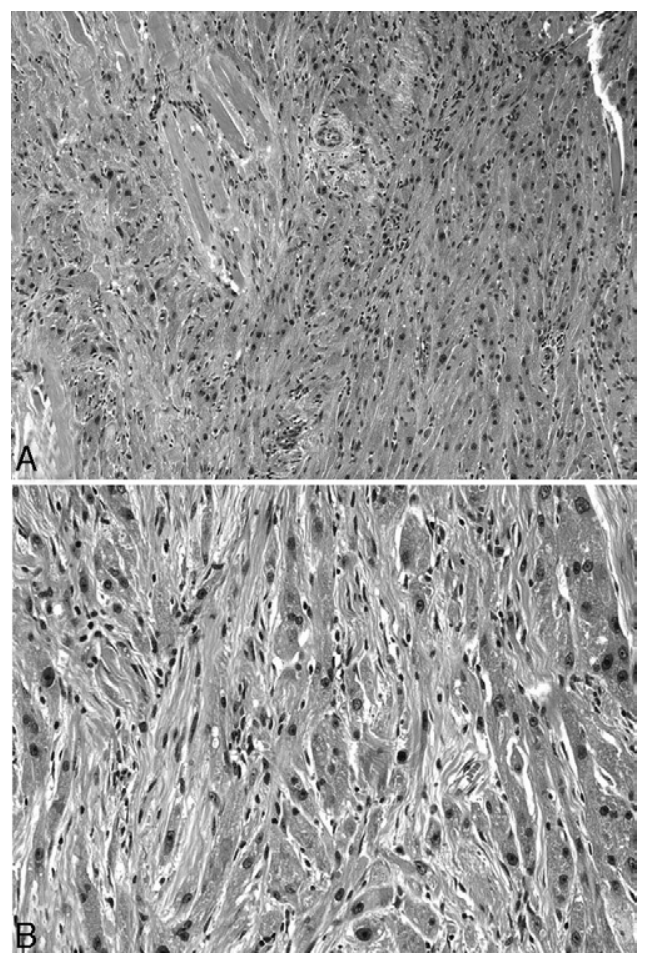

Figure 3. Infiltrative granular cell tumor. A, The dense cellular proliferation infiltrated the skeletal muscle (hematoxylin and eosin stain; original magnification $100 \times$ ). B, The higher magnification (hematoxylin and eosin stain; original magnification $200 \times$ ) demonstrates the characteristic abundant eosinophilic granular cytoplasm of the cells. The cellular spindling and presence of nucleoli was atypical.

\section{References}

1. Chatelain D, Terris B, Molas G, et al. [Infiltrating granular cell tumor of the esophagus: a description of two cases]. Ann Pathol. 2000;20:158-62.

2. Crawford ES, De Bakey ME. Granular-cell myoblastoma; two unusual cases. Cancer. 1953;6:786-9.

3. Farrell KH, Devine KD, Harrison EG Jr, et al. Granular cell myoblastoma of the esophagus. Incidence and surgical treatment. Ann Otol Rhinol Laryngol. 1973;82:784-8.

4. Goldblum JR, Rice TW, Zuccaro G, et al. Granular cell tumors of the esophagus: a clinical and pathologic study of 13 cases. Ann Thorac Surg. 1996;62:860-5.

5. Rella AJ, Conte AJ, Farrell JT. Granular cell myoblastoma of the esophagus. A case report. Arch Otolaryngol. 1963;78:715-8. 